\title{
I nterface pressure, pressure gradient with pressure ulcer development in Intensive Care Units
}

\author{
Supriadi $^{1}$, Tomoe Nishizawa ${ }^{2}$, Moriyoshi Fukuda ${ }^{2}$, Yuka Kon $^{2}$, Matsuo J unko ${ }^{3}$, Suriadi ${ }^{3}$, Okuwa \\ Mayumi $^{2}$, Nakatani Toshio ${ }^{2}$, Sugama J unko ${ }^{2}$, Sanada Hiromi ${ }^{4}$ \\ 1. School of Nursing Muhammadiyah Pontianak, West Borneo, Indonesia. 2. Department of Clinical Nursing, Graduate \\ School of Medical Science, Kanazawa University, Kodatsuno, Kanazawa, Japan. 3. Faculty Nursing, Osaka Medical College, \\ Takatsuki, Osaka, Japan. 4. Department of Gerontological Nursing/Wound Care Management, Graduate School of \\ medicine, The University of Tokyo, Tokyo, Japan.
}

Correspondence: Sugama Junko. Address: Department of Clinical Nursing, Graduate School of Medical Science, Kanazawa University, 5-11-80 Kodatsuno, Kanazawa 920-0942, Japan. Email: junkosgm@mhs.mp.kanazawa-u.ac.jp

Received: January 28, 2014

DOI : $10.5430 /$ jnep.v4n9p146
Accepted: June 24, 2014

Online Published: July 23, 2014

URL: http://dx.doi.org/10.5430/jnep.v4n9p146

\section{Abstract}

The pressure gradient can predict skin breakdown when combined with high pressure. We investigate the relationships between Peak Interface Pressure (PIP) and peak pressure gradient (PPG) for predicting and understanding the causes of pressure ulcers. Design of this research was a prospective cohort design. Pressure ulcers were identified and classified using the National Pressure Ulcer Advisory Panel and European Pressure Ulcer Advisory Panel. Interface pressure was measured at the patient's sacrum three times once every three days until pressure ulcers develop. The assessment was measured after the 24-hours monitoring period had expired for a newly admitted patient to the intensive care unit (ICU). The locations of the pressure ulcers were found using trace sheets. The 87 patients were obtained from two hospitals. The incidence of pressure ulcers was $12.6 \%$. The PIP was $66.2 \mathrm{mmHg}$ and PPG was $12.1 \mathrm{mmHg}$ for a pressure ulcer compared to without a pressure ulcer $(p<.01)$. The cut-off value for PIP was $50.0 \mathrm{mmHg}$ and PPG was $8.0 \mathrm{mmHg} / \mathrm{cm}$. The PIP > $50.0 \mathrm{mmHg}$ and PPG $>8.0 \mathrm{mmHg} / \mathrm{cm}$ were risk pressure ulcers. The correlation between the PIP and PPG were high correlation $(r=0.925)$. The PIP and PPG may be a useful indicator for the development of pressure ulcers.

\section{Key words}

Interface pressure, Peak interface pressure, Pressure gradient, Peak pressure gradient, Pressure ulcer, Intensive care unit, Incidence pressure ulcer, Category of pressure ulcer

\section{I ntroduction}

The study was carried out in Indonesia where the incidence of pressure ulcers was $28.4 \%$ in intensive care units (ICUs) ${ }^{[1]}$. Suriadi et al. ${ }^{[2]}$ found that the incidence of pressure ulcers was higher in Indonesia than in other Asian countries such as China $2.1 \%{ }^{[3]}$, South Korea $10.5 \%{ }^{[4]}$, and Japan $11.2 \%{ }^{[5]}$ and other countries worldwide such as Germany $3.3 \%{ }^{[6]}$, Spain $12.4 \%{ }^{[7]}$, and the United States $16 \%{ }^{[8]}$. The high incidence of pressure ulcers in Indonesia should be a major concern for all healthcare providers that aim to prevent the formation of pressure ulcers and it is a priority for nursing research in Indonesia. 
Prevention and reduction of the occurrence of pressure ulcers in Indonesian ICUs needs to be studied. Suriadi, Sanada H, Sugama J, Thigpen B, Subuh M (2008) ${ }^{[1]}$ reported that the risk factors for pressure ulcer development were interface pressure (IP), temperature, and smoking. When a patient in the ICU receives a medication to decrease the body temperature, the body temperature may be febrile to normal. The patient may have had a smoking habit before entering the hospital. The IP may be related to pressure ulceration because the pressure ulcer develops from above toward the direction of the sacrum. The National Pressure Ulcers Advisory Panel (2007) ${ }^{[9]}$ define IP is the force per unit area that acts perpendicularly between the body and the support surface. Suriadi et al. ${ }^{[2]}$ in their study found that the IP was significant to predict the occurrence of pressure ulcers with a cut-off point more than $35 \mathrm{mmHg}$ in supine position. One study reported the ICU patients sitting out of bed have a high seating IP; specifically, the PIP (Peak Interface Pressure) was 90-101 $\mathrm{mmHg}$ in patients who used a regular cushion ${ }^{[10]}$. Unfortunately, the study was not related to the occurrence of pressure ulcer development. Research by Suriadi et al. ${ }^{[2]}$ confirms the findings that IP was an important risk factor that contributes to pressure ulcer development. Therefore, it can be postulated that a lower IP was likely to decrease the risk of pressure ulcer development.

The IP is not the only factor that contributes to the occurrence of pressure ulcers, but the Peak Pressure Gradient (PPG) also. Mueller MJ et al. ${ }^{[11]}$ found that the PPG can predict skin breakdown of the plantar surface in patients with diabetes. The PPG is the highest pressure on the Pressure Gradient (PG) or in the direction of the pressure derivative at the allocation of the peak pressure on the surface of the body, and the PG is the pressure differential or the change in pressure over a distance and measured with a change in $\mathrm{mmHg}$ per $\mathrm{cm}^{2}$ or inch ${ }^{[12]}$. The PPG measured in several studies was conducted in patients with diabetic neuropathy and assessed the PPG in patients that contributed to skin damage. A previous study showed that the PPG was $143 \%$ higher in the front of the foot than in the rear of the foot, even when compared with peak plantar pressure of the diabetic patient. The PPG must be a better indicator than the peak plantar pressure alone in distinguishing patients at risk for skin breakdown ${ }^{[11]}$. The study was not associated with the occurrence of pressure ulcer development.

Pressure on the surface of the body with the support surface is at risk factor for pressure ulcer development, but it is not merely pressure alone that causes a pressure ulcer; there is a possibility of other factors, namely the PG. Until now, there was no evidence of pressure ulcer development by the PG. There does not yet appear to be a specific threshold of PG that predicts skin breakdown. A study to investigate the relationship between PIP and PPG with pressure ulcers development was needed and the outcomes could be used to reduce the incidence of pressure ulcers in Indonesia. Essentially, the goal of this study is to determine the relationships between PIP and PPG for prediction of pressure ulcer development in ICUs patients.

\section{Methods}

\subsection{Materials}

The IP was recorded by a scanning aid device namely Palm Q; Cape Co. Ltd., Yokosuka, Japan (see Figure 1). The dimensions and weight were width $6.5 \mathrm{~cm} \mathrm{X}$ length $7.5 \mathrm{~cm} \mathrm{X}$ thick $3.5 \mathrm{~cm}$ and 160 gram. It has five sensors per square centimeter, each in a fan shapes, flexible sensors sized width $13 \mathrm{~cm} \mathrm{X}$ length $13 \mathrm{~cm}$, and a cable length of $75 \mathrm{~cm}$. The accuracy of this instrument was $0-200 \mathrm{mmHg}$, and $\pm 3 \mathrm{mmHg}$, (at $0-40^{\circ} \mathrm{C}$ ), respectively. The correlation coefficient of pressure evaluator scores for interrater test was 0.992 to 1.000 and 0.737 for intra rater test. Then the validity test of pressure evaluator was significant difference $(p<.001)$ between patients with pressure ulcer and patients without pressure ulcer $^{[13]}$.

A prospective cohort design was conducted between March and October 2011. The research was conducted at two hospitals in Pontianak, Indonesia. Ten (10) of 446 beds in hospital A (Soedarso General Hospital) and 16 of 296 beds in hospital B (St. Antonius General Hospital) were allotted to the ICUs. 


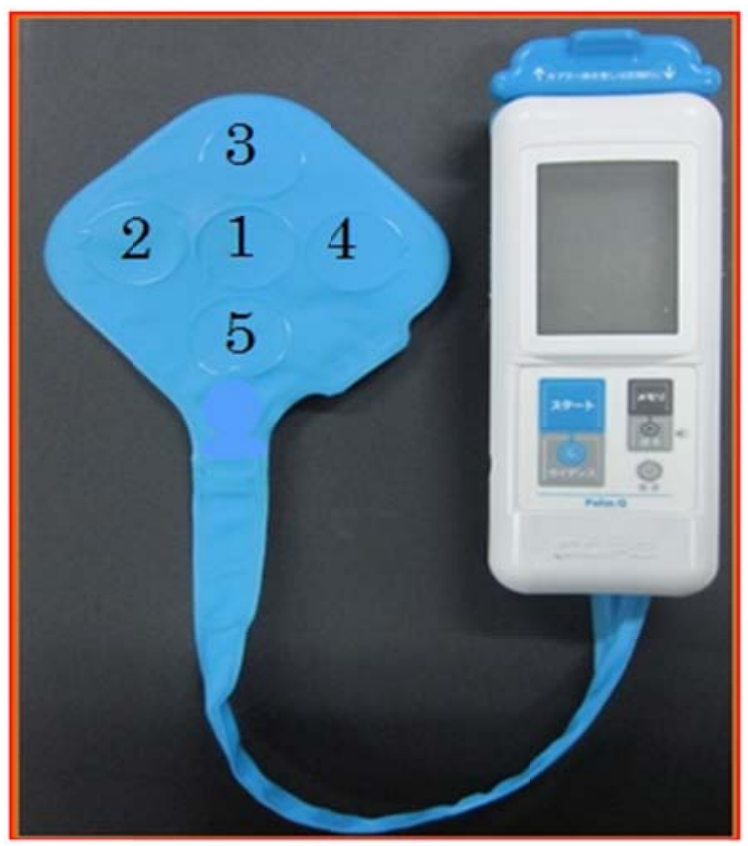

Figure 1. Palm-Q Device

The inclusion criteria were patients $\geq 18$ years of age, first admission to the ICU, and immobilization. Patients had an expected length of stay of at least 2 days (48 hours) after initial data collection, and gave informed consent. All subjects were required to be free of pressure ulcers at the beginning of the study. The exclusion criteria were patients who could not be manipulated (difficult to identify the skin condition every day and bad conditions) and any patient who did not wish to participate in the study. A convenience sample was patients in ICUs. The sample size of the follow-up cohort was calculated so that the incidence of pressure ulcers could be measured with a relative precision of $40 \%$, and a confidence level of $95 \%^{[14]}$.

The measurements were on the pressure scanning aid on the area $4 \mathrm{~cm}$ below the sacrum in the supine position. The measurement was divided into three areas (central, right, and left areas) of the sacrum (see Figure 2). Interface pressure measurement and pressure gradients were taken at the patient's sacrum every three days and repeated three times during each assessment until pressure ulcers occurrence. The skin over the sacrum of all patients was observed every day until discharge from the ICU and a picture was taken every day with a digital camera. The study recorded the gender, age, medical diagnosis, type of mattress, body mass index, Braden score, Suriadi Sanada (SS) scale, length of stay, and APACHE II score. After a pressure ulcer developed, the occurrence, category, and location of the pressure ulcers were assessed every day. The category system was based on the National Pressure Ulcer Advisory Panel (NPUAP) and the European Pressure Ulcer Advisory Panel ${ }^{[15]}$. For patients who did not develop a pressure ulcer, the IP was used for the first assessment. For patients who did develop a pressure ulcer, the value obtained in the assessment before the pressure ulcer developed was used. After selecting the IP data, we calculated the PIP and PPG values that had the highest values for the IP and PG. According to research by Mueller MJ et al. ${ }^{[10]}$ the PG values were calculated by subtracting the pressure in each node around the peak pressure from that in the adjacent node and dividing by the distance between the central portions of the sensor. The PG in this study was calculated as follows: PIP minus IP divided distance between by sensor to sensor. So PG is use $\mathrm{mmHg} / \mathrm{cm}$ as unit.

This formula is $\mathrm{PG}=\frac{(\mathrm{PIP}-\mathrm{IP})}{\text { Distance }}$

The distance formula is: $\mathrm{c}^{2}=\mathrm{a}^{2}+\mathrm{b}^{2}$ 


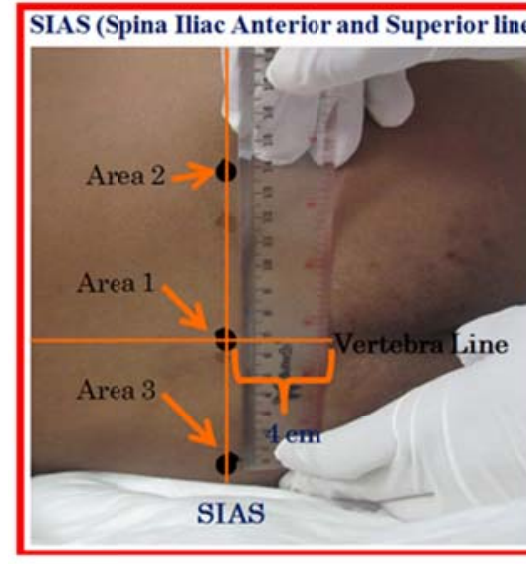

The measurement was on the sacrum area, right, and left buttock.

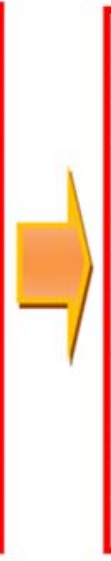

The location divided three The location divided three
areas (center, right, and left)

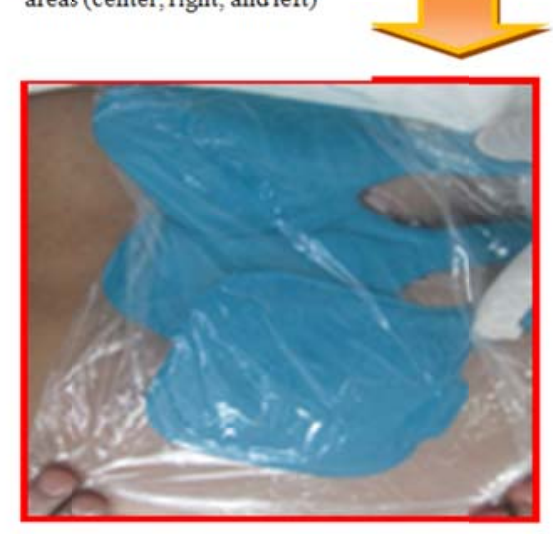

The measurement was on the sacrum area, right, and left buttock.

Figure 2.The measurement of pressure scanning aid for interface pressure

\subsection{Data analysis}

Demographic and clinical characteristics data were used as descriptive analysis. The means values and standard deviations (SD) of the PIP and PPG were used and a t-test was used to compare the means in patients with and without pressure ulcers. The diagnostic probability was used to calculate the range of the PIP, and a Receiver Operator Characteristic (ROC) curve was used to confirm the PIP cut-off and Area under Curve (AUC) values. When the cut-off value for a continuous diagnostic variable is increased (assuming that larger values indicate an increased chance of a positive outcome), the proportions of both true and false positives decreases. These proportions are the sensitivity and 1 - specificity, respectively. A graph of sensitivity against 1 - specificity is called a receiver operating characteristic (ROC) curve ${ }^{[16]}$. The Pearson correlation coefficient between PIP and PPG was used. All analyses were performed with the Statistical Product and Social Science software (version 15; SPSS, Inc., Chicago, IL, USA) and significance was set at a $p<.05$.

\subsection{Ethical considerations}

Before the study was conducted, the researchers obtained permission from the Ethics Committee of Kanazawa University (\#302). The clinical research ethics committees in both hospitals approved the study protocol. Patients as subjects who wished to participate were then informed of their rights and the ability to drop out of the study at any time for their own reasons. Next, they obtained inform consent either by the patients themselves or family members. There were six nurses who helped complete this study by observing the patients' safety during investigation. 


\section{Results}

\subsection{Demographic data and clinical characteristics}

A total of 108 patients were enrolled after meeting the initial study inclusion criteria. Of those, 21 patients were excluded because there were 18 patients because only one-time inspection and 3 patients within continence associated dermatitis and the remaining 87 patients participated in this study. The patients were male (47.54\%), and female (52.46\%) and mean age was $44.1(\mathrm{SD} \pm 16.9)$ years. The mean length of stay in the ICU was $7.9(\mathrm{SD} \pm 6.2)$ days, the mean APACHE II score was $11.5(\mathrm{SD} \pm 4.9)$, $\mathrm{SS}$ scale was $3.49(\mathrm{SD} \pm 2.5)$, Braden scale was $11.22(\mathrm{SD} \pm 1.3)$, body mass index (BMI) was 25.5 $(\mathrm{SD} \pm 5.0)$, then diagnoses for ICU admissions included head injury (39.1\%), stroke (36.8\%), post operation (16.1\%) and others $(8.0 \%)$ (see Table 1$)$.

Table 1. Demographic and characteristics of patients $(n=87)$

\begin{tabular}{ll}
\hline Subject & \\
\hline Gender n (\%) & $40(46.0 \%)$ \\
Male & $47(54.0 \%)$ \\
Female & $44.1( \pm 16.9)$ \\
Age mean (SD) & $7.9( \pm 6.2)$ \\
Length of stay mean (SD) & $11.5( \pm 4.9)$ \\
APACHE mean (SD) & $3.49( \pm 2.5)$ \\
SS scale mean (SD) & $11.22( \pm 1.3)$ \\
Braden scale mean (SD) & $25.5( \pm 5.0)$ \\
BMI mean (SD) & \\
Diagnoses n (\%) & $34(39.1 \%)$ \\
Head injury & $32(36.8 \%)$ \\
Stroke & $14(16.1 \%)$ \\
Post Operation & $8(19.0 \%)$ \\
Others & \\
Mattresses n (\%) & $63(72.4 \%)$ \\
Foam mattress & $24(27.6 \%)$ \\
Air mattress &
\end{tabular}

\subsection{PIP and PPG}

The PIP mean was 66.2 and $\mathrm{SD} \pm 42.0 \mathrm{mmHg}$ for pressure ulcer development and the PIP mean was 42.7 and $\mathrm{SD} \pm 14.8$ $\mathrm{mmHg}$ with no pressure ulcer development, significant $(p)$ was 0.000 and the PPG mean was 12.1 and SD \pm 10.2 $\mathrm{mmHg} / \mathrm{cm}$ with pressure ulcer development and the PPG mean was 6.6 and $\mathrm{SD} \pm 3.6 \mathrm{mmHg} / \mathrm{cm}$ with no pressure ulcer development, significant ( $p$ ) was .001 (see Table 2).

Table 2. The comparison of PIP and PPG of the pressure ulcer positive and pressure ulcer negative

\begin{tabular}{lccc}
\hline & $\begin{array}{l}\text { Pressure Ulcer } \\
(\mathbf{n}=\mathbf{1 1})\end{array}$ & $\begin{array}{l}\text { No Pressure Ulcer } \\
(\mathbf{n}=\mathbf{7 6})\end{array}$ & p value \\
\hline PIP (mmHg) & & & $.000^{*}$ \\
mean \pm SD & $66.2 \pm 42.0$ & $42.7 \pm 14.8$ & \\
Range & $35.0-160.0$ & $14.5-89.5$ & \\
PPG (mmHg) & $12.1 \pm 10.2$ & $6.6 \pm 3.6$ & $.001 *$ \\
mean \pm SD & $5.0-37.9$ & $1.3-16.0$ & \\
Range & & & \\
\hline
\end{tabular}

*Significance $p<.05$ 


\subsection{Pressure ulcer development}

The eleven (11) of 87 patients developed pressure ulcers. The pressure ulcer development of grade I was $45.5 \%$, grade II was $36.4 \%$ and grade IV was $18.1 \%$, respectively (see Table 3 ). The pressure ulcers were located on the right buttock for 4 patients, right and left buttocks in 3 patients, coccyx for 3 patients of central position and sacrum for 1 patient of central position (see Figure 3 a, b, c, and d).

Table 3. Category and incidence of pressure ulcer $(n=11)$

\begin{tabular}{ll}
\hline Category or Grade of Pressure Ulcers & (n \%) \\
\hline I & $5(45.5)$ \\
II & $4(36.4)$ \\
III & $0(0.0)$ \\
IV & $2(18.1)$ \\
Pressure ulcers (n \%) & \\
Pressure ulcer positive & $11(12.6 \%)$ \\
Pressure ulcer negative & $76(87.4 \%)$ \\
\hline
\end{tabular}
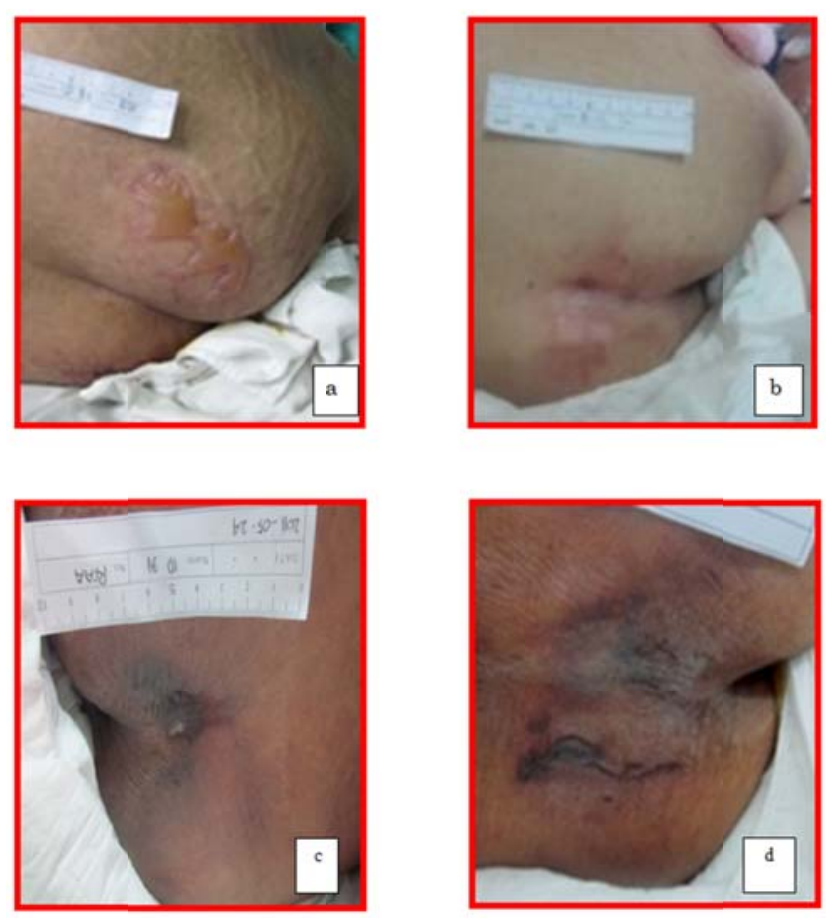

Figure 3. a) Pressure ulcers were located on the right buttock, b) Pressure ulcers were right and left buttock area, and c) Pressure ulcer on the coccyx of central area, and d) Pressure ulcer on the sacrum of central area.

\subsection{ROC Curve PIP and PPG}

The PIP has a cut-off score of $50.0 \mathrm{mmHg}$ and was designated in the current study with a sensitivity of $45.5 \%$, a specificity of $31.6 \%$, a positive predictive value (PPV) of $29.2 \%$, and a negative predictive value (NPV) of $83.3 \%$, while the positive likelihood ratio was 2.2 with an overall accuracy of $59.8 \%$. The ROC curves constructed an AUC of 0.668 with $95 \%$ CI, 0.490-0.826 (see Figure 4). The PPG has a cut-off value of $8.0 \mathrm{mmHg} / \mathrm{cm}$ and was designated in the current study with a sensitivity of $36.4 \%$, a specificity of $22.4 \%$, a PPV of $26.8 \%$, and a NPV of $80.0 \%$, while the positive likelihood ratio 1.15 with an overall accuracy of $62.2 \%$. The ROC curves constructed an AUC of 0.701 with 95\% CI, 0.561-0.841 (see Figure 5). The correlation between PIP and PPG was high correlation (see Figure 6). 


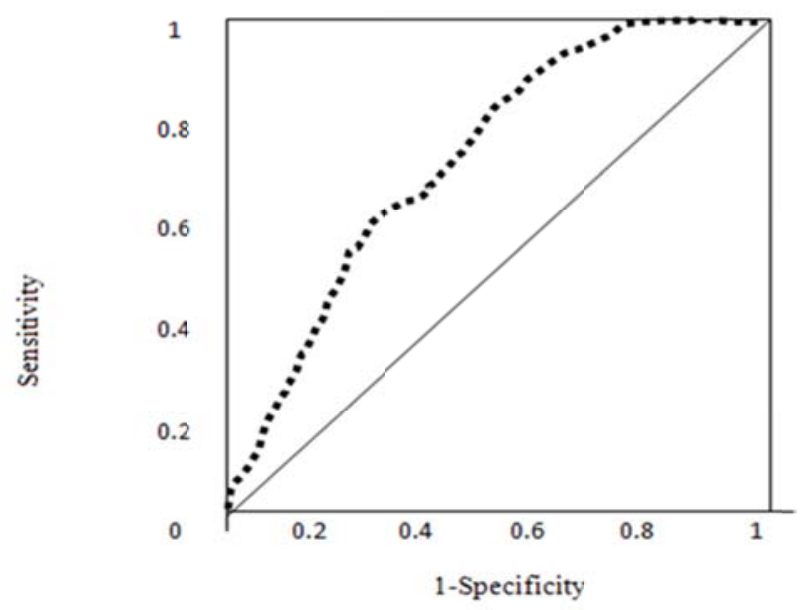

Figure 4. Peak interface pressures receiver operator characteristic (ROC) curve. The ROC curve plot of sensitivity and 1-specificity or each possible score of the peak interface pressure; the area under curve (AUC) was 0.658 (confidence interval, 0.490-0.826).

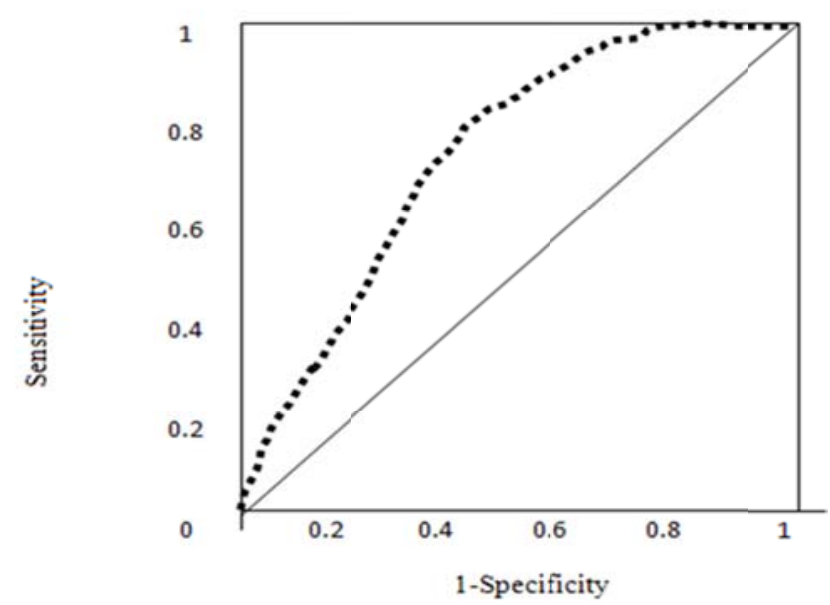

Figure 5. Peak pressures gradient receiver operator characteristic (ROC) curve. The ROC curve plot of sensitivity and 1-specificity or each possible score of the peak pressures gradient; the area under curve (AUC) was 0.701 (confidence interval, 0.561-0.841).

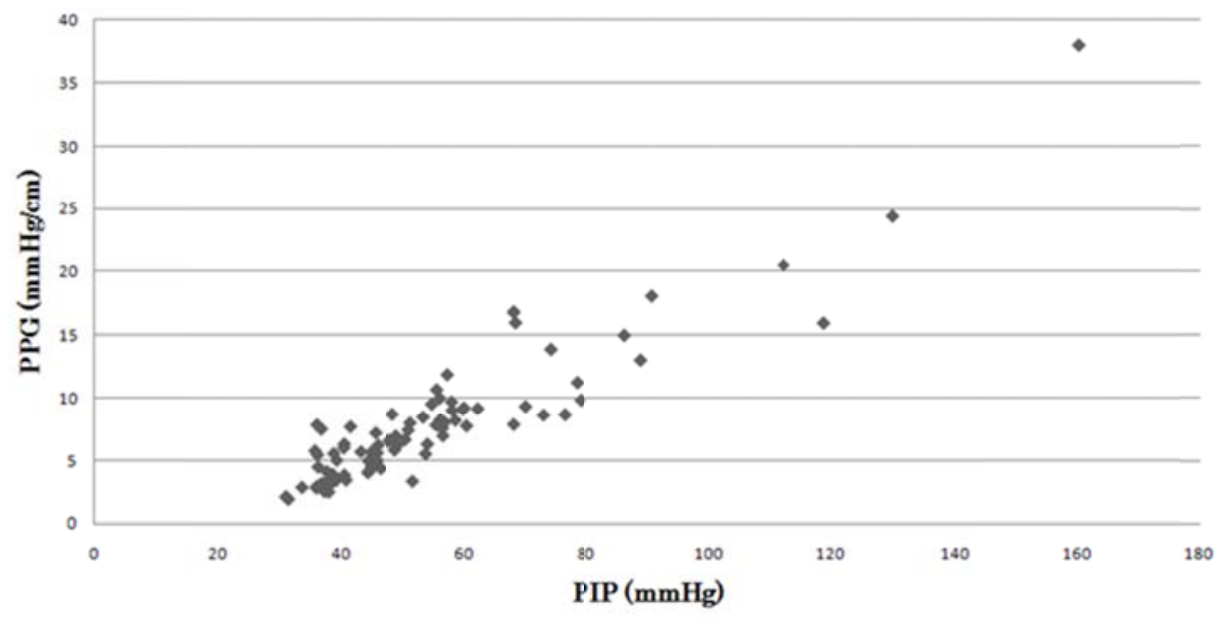

Figure 6. Correlation between peak interface pressure (PIP) and peak pressure gradient (PPG; $r=0.925$ )

\section{Discussion}

The incidence of pressure ulcers in this study was $12.6 \%$. The incidence in this study was lower than that reported in previous study in Indonesia ${ }^{[1]}$. This may be explained by the fact that the current study was conducted in an intensive care unit which used air and foam mattresses and the previous study used standard mattresses made in Indonesia. The risk of developing a pressure ulcer for patients who use standard mattresses is high ${ }^{[1]}$.

The research showed that PIP and PPG values were significantly higher with pressure ulcers than without pressure ulcers. PIP and PPG had a very strong relationship to predict pressure ulcer development. This research found that PIP and PPG were important risk factors that contribute to pressure ulcer development.

Okuwa et al. ${ }^{[13]}$ that research used the same instrument for elderly people patients with our research. A cut-off value 50 $\mathrm{mmHg}$ has been used for prediction of patients at risk of developing pressure ulcers in ICU. However, the findings of the 
current study do not support the previous research that was reported by Suriadi et al. ${ }^{[2]}$. There is a reason that there are differences in the tools used for measurement of IP. Our research used a multi-pad with five sensors, whereas in previous studies a multi-pad with three sensors were used, a multi pad three sensors have smaller size than five sensors, so five sensors can measure of sacrum or buttock wider area and the coefficient of variance was $8.96 \%$. The precision of the replicates in the current study was not different with respect to the way the replicates or individual tests were performed. Another study also postulated that IP is a factor in pressure ulcer development ${ }^{[17]}$.

The current study showed that the predictive validity of PIP by a ROC curve was weak, but a PIP value of $50.0 \mathrm{mmHg}$ with sensitivity, specificity, and PPV was a lower value and the NPV was highest and the accuracy of the PIP (59.8\%). NPV was the highest value, which indicates that the probability of patients with no pressure ulcer development. Thus, a PIP $(\leq$ $50.0 \mathrm{mmHg}$ ) was not predictive of the risk of pressure ulcer development, but PIP $>50.0 \mathrm{mmHg}$ was predictive of the risk pressure ulcer development.

The research showed that the PPG was adequate with pressure ulcer development compared to no pressure ulcer development. The current study showed that a PPG of the $8.0 \mathrm{mmHg} / \mathrm{cm}$ was not predictive for pressure ulcer development but PPG more than $8.0 \mathrm{mmHg} / \mathrm{cm}$ was predictive for pressure ulcer development. Mueller MJ et al. ${ }^{[10]}$ reported that the average of PPG was 143\% substantially higher in the front of the foot than in the rear of the foot and the PPG was substantially higher and may be a useful indicator of skin trauma because spatial changes in high plantar pressures may identify high stress concentrations within the soft tissue. The concept of a Pressure Gradient contributing to potentially harmful internal stresses has been conducted ${ }^{[1]}$. A large change in pressure across the surface of the skin (a high PPG) may result in an excessive internal stress response ${ }^{[18]}$ and resultant shearing of soft tissues that may contribute to tissue injury and breakdown ${ }^{[19]}$. There are no previous studies investigating PPG with and without pressure ulcer development. Interestingly, PPG was the only pressure variable in this study that distinguished patients with and without pressure ulcer development. Our research provides data on the relationship between the PPG with the development of pressure ulcers, although not as an indicator of the development of pressure ulcers that occur in the clinical setting.

Potential limitations of this research that require further consideration include that this research was an assessment of pressure ulcers focused on the sacrum only. Body shape and weight the patient's, skin condition, medical condition and variables associated with care are outside the scope of this study.

\section{Conclusion}

The research showed that the incidence of pressure ulcers of both hospitals was $12.6 \%$ at the sacrum and buttocks. This study indicates that a significance difference exists between PIP and PPG with pressure ulcer development and no pressure ulcer development. The PIP and PPG may be a useful indicator for predicting the development of pressure ulcers between patients with and without pressure ulcers. This may reduce the costs (human and fiscal) of patient care and also the institution, which will be an incentive to promote future research in the prevention of pressure ulcers in a clinical setting. In this study it was postulated that IP and PG evaluators that were identified to predict pressure ulcer development, so the tools can be used to prevent the development of pressure ulcer risk in patients and as a nursing intervention assessment. This is a new assessment for predicting pressure ulcer using PG evaluator and it is effective to screen ICU patients who have no risk of pressure ulcer. The results of this study can improve nursing care by performing measurements on the body surface between the mattress by means of tilt left and right to prevent pressure sores.

\section{Acknowledgments}

Two institutions provided the primary research support and technical assistance for these research were Soedarso General Hospital in Pontianak Indonesia and St. Antonius General Hospital in Sei Jawi Pontianak, Indonesia. I am grateful to the hospital Directors who provided support for this study. 


\section{Reference}

[1] Suriadi, Sanada H, Sugama J, Thigpen B, Subuh M. Development of new a risk assessment scale for predicting pressure ulcers in an intensive care unit. Nursing in Critical Care. 2008; 13: 34-3. PMid:18226053http://dx.doi.org/10.1111/j.1478-5153.2007.00250.x

[2] Suriadi, Sanada H, Sugama J, Kitagawa A, Thigpen B, Kinosita, et al. Risk factor in the development of pressure ulcer in an intensive care unit in Indonesia. International Wound Journal. 2007; 4: 208-15.

PMid:17924877http://dx.doi.org/10.1111/j.1742-481X.2007.00315.x

[3] Kwong E, Pang S, Wong T, Ho J, Shao-Ling X, Li-jun T. Predicting pressure ulcer risk with the modified Braden, Braden, and Norton scales in acute care hospitals in mainland China. Appl Nurs Res. 2005; 18: 122-128.

PMid:15991112http://dx.doi.org/10.1016/j.apnr.2005.01.001

[4] Kim EK, Lee SM, Lee E, Eom MR. Comparison of the predictive validity among pressure ulcer risk assessment scales for surgical ICU patients. Aust J Adv Nurs. 2008; 26: 87-4.

[5] Kaitani T, Tokunaga K, Matsui N, Sanada H. Risk factors related to development of pressure ulcers in the critical care setting. Journal of Clinical Nursing. 2010; 19: 414-21. PMid:20500281 http://dx.doi.org/10.1111/j.1365-2702.2009.03047.x

[6] Shahineman, SM, Dassen T, Ruud JG. Incidence, prevention and treatment of pressure ulcers in intensive care patients: A longitudinal study. International Journal of Nursing Studies.2008; 46: 413-21. PMid:18394626 http://dx.doi.org/10.1016/j.ijnurstu.2008.02.011

[7] Fife C, Otto G, Capsuto GE, Brand K, Lyssy K, Murphy K, Short C. Incidence of pressure ulcers in a neurologic intensive care unit. Critical Care Medical Journal. 2001; 29:283-90.http://dx.doi.org/10.1097/00003246-200102000-00011

[8] Manzano F, Navarro MJ, Roldan D, Moral MA, Leyva I, Guerrero C, et al. Pressure ulcer incidence and risk factors in ventilated intensive care patients. Journal of Clinical Care. 2009; 20: 1-8.

[9] Ruth A. B., \& Denise. P.N. Acute \& Chronic Wounds: Current Management Concepts. (3th Ed, pp. 236). American: Mosby, Inc; 2007.

[10] William TN, Leslie GD, Bingham R, BrearleyL. Optimizing seating in the intensive care unit for patients with impaired mobility.American Journal of Critical Care Nurse. 2011; 20:19-27. PMid:21196564http://dx.doi.org/10.4037/ajcc2011239

[11] Mueller MJ, Zou D, Lott DJ. Pressure gradient as an indicator of plantar skin injury.Journal Diabetes Care. 2005; 28(12): 2908-912. http://dx.doi.org/10.2337/diacare.28.12.2908

[12] Brienza DM, Geyer MJ, Sprigle S, Zulkowski K. Pressure redistribution: seating, positioning, and support surface. In Baranoski S, Ayello EA (Ed.), Wound care essentials: practice principles (second edition, pp 202-28). American: Lippincott Williams \& Wilkins, 2004.

[13] Okuwa M, Yusuf S, Supriadi, Kumagai A, Iizaka S, Sugama J, Sanada H. Reliability and Validity of a New Multi-pad Pressure Evaluator in the Clinical Setting. Japan Journal Pressure Ulcer. 2012. 14:2.

[14] Lwanga K.S and LemeshowS. Sample size determination in health studies; a practical manual [Software] version]. World Health Organization Geneva. 1998.

[15] Black J, Baharestani M, CuddiganJ, Dormer B, Edsberg L, LangemoD, et al. National Pressure Ulcer Advisory Panel's Updated Pressure Ulcer Staging System. Dermatology Nursing.2007; 19(4): 343-349. PMid:17874603

[16] Bewick V, Cheek L, Ball D. Statistic Review 13: Receiver ooperating characteristic curves. Critical Care. 2004. 8: 508-512.PMid:15566624http://dx.doi.org/10.1186/cc3000

[17] Mimura M, Ohura T, Takahashi M, Takahashi M, Kajiwara R, Ohura N. Mechanism leading to the development of pressure ulcers based on shear force and pressures during a bed operation: Influence of body types, body positions, and knee positions. Wound Repair and Regeneration. 2009; 17:789-96. PMid:19821961 http://dx.doi.org/10.1111/j.1524-475X.2009.00540.x

[18] Mueller MJ, Zou D, Bohnert KL, Bohnert KL, Tuttle LJ, Sinacore DR. Plantar stresses on the neuropathic foot during barefoot walking.Journal Physical Therapy. 2008; 88:1375-384. PMid:18801862http://dx.doi.org/10.2522/ptj.20080011

[19] Zou D, Mueller MJ, Lott DJ. Effect of peak pressure and pressure gradient on subsurface shear stresses in the neuropathic foot.Journal of Biomechanics. 2006; 40:883-90. PMid:16677657http://dx.doi.org/10.1016/j.jbiomech.2006.03.005 